\title{
ADSORPTION OF LEAD (II) IONS ONTO DIATOMITE FROM AQUEOUS SOLUTIONS: MECHANISM, ISOTHERM AND KINETIC STUDIES
}

\author{
SALMAN T. ${ }^{1}$ \\ TEMEL F.A. ${ }^{2}$ \\ TURAN N.G. ${ }^{1, *}$ \\ ARDALI Y. ${ }^{1}$
}

\author{
${ }^{1}$ Ondokuz Mayis University, Engineering Faculty \\ Dept. of Environmental Engineering, 55200, Samsun, Turkey \\ ${ }^{2}$ Giresun University, Engineering Faculty \\ Dept. of Environmental Engineering, 28200, Giresun, Turkey
}

*to whom all correspondence should be addressed: e-mail: gturan@omu.edu.tr

\section{ABSTRACT}

This study presents an evaluation of diatomite as a low cost adsorbent for $\mathrm{Pb}$ (II) removal from aqueous solutions under various conditions. The results demonstrate that adsorption of $\mathrm{Pb}$ (II) is strongly dependent on the $\mathrm{pH}$ of the solution. The effect of $\mathrm{pH}$ on adsorption of $\mathrm{Pb}$ (II) on diatomite was studied by varying $\mathrm{pH}$ from 2 to 12 at $20^{\circ} \mathrm{C}$. In the $\mathrm{pH}$ range of 2.0-4.0, the percentage of $\mathrm{Pb}$ (II) adsorbed increases slightly as the $\mathrm{pH}$ increases. At $\mathrm{pH}>4$, the percentage of $\mathrm{Pb}$ (II) adsorbed decreases with increasing $\mathrm{pH}$ because hydrolysis and precipitation begin to play an important role in the sorption of $\mathrm{Pb}$ (II). At pH 4, the maximum adsorption capacity of diatomite was found to be $26 \mathrm{mg} / \mathrm{g}$. The adsorption isotherms of $\mathrm{Pb}$ (II) on diatomite can be described well by the Freundlich model. The regression equation coefficients were calculated and the data fitted to a second-order kinetic equation for removal of $\mathrm{Pb}$ (II) ions. The high adsorption capacity of diatomite makes it a suitable low-cost material for the removal of $\mathrm{Pb}$ (II) from aqueous solutions.

Keywords: Adsorption, lead, low-cost adsorbent, isotherm, kinetic

\section{Introduction}

One of the most important environmental issues to be solved today is the presence of heavy metals from industrial wastewaters. Due to their toxicity and nonbiodegradable nature, heavy metals cause environmental and public health problems (Xuea et al., 2009; Shi et al., 2009). Various techniques have been developed to remove heavy metals from aqueous solutions. These techniques include chemical precipitation, reverse osmosis, ion exchange, and adsorption (Swayampakula et al., 2009; Aguado et al., 2009; Yu et al., 2000; ljagbemi et al., 2009; Qdaisa and Moussab, 2004; El-Bayaa et al., 2009). Among them, adsorption is considered to be a particularly low-cost and effective process for the removal of heavy metals from aqueous solutions (Bhattacharya et al., 2006; Lin and Juang, 2002; Cheremisinoff, 1995).

The most commonly used adsorbent is activated carbon and it generally has high metal adsorption capacity. Although activated carbon is effective in the removal of metal ions from wastewater, it is expensive and requires chelating agents to enhance its performance, thus increasing treatment cost (Oliveira et al., 2005). For the past two decades, researchers have focused on using low-cost, efficient sorbents for heavy metal adsorption. Furthermore, the sorption behavior of several natural materials and waste products has also been investigated (Mittal et al., 2006; Şölener et al., 2008; Zheng et al., 2007). These include clay minerals (Ijagbemi et al., 2009 ; Márquez et al., 2004), agricultural by-products (Sud 
et al., 2008; Šćiban et al., 2008), some aquatic plants (Axtell et al., 2003; Keskinkan et al., 2004), and microorganisms (Li et al., 2004; Yan and Viraraghavan, 2003). Most of these studies have shown that natural products can serve as good sorbents for heavy metals.

Diatomite is a siliceous sedimentary rock composed of an amorphous form of silica $\left(\mathrm{SiO}_{2} . n \mathrm{H}_{2} \mathrm{O}\right)$ containing a small amount of microcrystalline material. It has a unique combination of physical and chemical properties such as high porosity, high permeability, small particle size, large surface area, and low thermal conductivity. In addition, it is available in Turkey and in various locations around the world. Therefore, diatomite has been successfuly used as adsorbent for the removal of heavy metals (Khraisheh et al., 2004; Sheng et al., 2009).

The aim of this study is to investigate the adsorption properties of diatomite. The equilibrium adsoption data was applied to the Langmuir, Freundlich, and Dubinin-Radushkevic (D-R) isotherm models. Adsorption experiments were performed in batch systems, using $\mathrm{Pb}$ (II) initial concentration, $\mathrm{pH}$ of solution, and contact time as variables.

\section{Materials and methods}

Diatomite samples were obtained from Çankırı-Çerkeş Basin of Turkey. The physicochemical properties of diatomite as reported by Aruntaş et al., (1998) are given in Table 1 (El-Said, 2010). For the experimental studies, the sample was washed with distilled water in order to remove any non-adhesive impurities and small particles, and then, dried at $70^{\circ} \mathrm{C}$ for $24 \mathrm{~h}$ to remove moisture. The dried samples were sieved and a range of $0.5-1.0 \mathrm{~mm}$ of particle size of diatomite was used in the remainder of the experiments.

Table 1. The physicochemical properties of diatomite

\begin{tabular}{lc}
\hline Parameters & Value \\
\hline Moisture content, \% & 80 \\
\hline Water retention, \% & 182 \\
\hline Spesific gravity, $\mathrm{g} \mathrm{mL}^{-1}$ & 1.9 \\
\hline $\mathrm{pH}$ & 7.3 \\
\hline
\end{tabular}

All chemicals used in the experiments were purchased in analytical grade. The $\mathrm{Pb}$ (II) stock solution was prepared by dissolving $\mathrm{Pb}(\mathrm{NO})_{3}$ in distilled water.

The adsorption of $\mathrm{Pb}$ (II) onto diatomite was investigated by using batch systems. The adsorption capacity for diatomite was determined by adding $0.1-2.0 \mathrm{~g}$ of adsorbent to $100 \mathrm{~mL}$ of solutions of varying concentrations $\left(1,10\right.$, and $\left.100 \mathrm{mg}^{-1}\right)$. The system was adjusted to the desired $\mathrm{pH}$ varying from 2 to 8 by adding negligible volumes of $\mathrm{NaOH}$ or $\mathrm{HCl}$. After the suspensions were shaken $24 \mathrm{~h}$, the solid and liquid phases were seperated by filtration. $\mathrm{Pb}$ (II) ions in the liquid phase were analysed using an atomic absorption spectroscopy. A UNICAM 929 model flame atomic absorption spectrophotometer with deuterium-lamp bacground correction was used for the determination of $\mathrm{Pb}$ (II). The measuring conditions were as follows: UNICAM hollow cathode lamp, $10 \mathrm{~cm}$ 1-slot burner, air-acetylene flame (fuel gas flow-rate $1.20\left(\mathrm{~min}^{-1}\right), 0.5 \mathrm{~nm}$ spectral bandwidth, and $7 \mathrm{~mm}$ burner height. The wavelength and the lamp current of $\mathrm{Pb}$ (II) was respectively $217 \mathrm{~nm}$ and $5 \mathrm{~mA}$.

\section{Results and discussion}

\subsection{Effect of $p H$}

The $\mathrm{pH}$ of the solution is an important controlling parameter for the adsorption of heavy metals on the sorbents and influences the metal speciation and surface metal binding sites. The effect of $\mathrm{pH}$ on the adsorption of $\mathrm{Pb}$ (II) at different initial $\mathrm{Pb}$ (II) concentrations $\left(1,10\right.$, and $\left.100 \mathrm{mg} \mathrm{l}^{-1}\right)$ at $25^{\circ} \mathrm{C}$ is shown in Fig. 1. 
The results show that adsorption of $\mathrm{Pb}$ (II) onto diatomite is affected by $\mathrm{pH}$. This is partly due to the fact that hydrogen ion $\left(\mathrm{H}^{+}\right)$themselves are strong competing ions and partly that the solution $\mathrm{pH}$ influence the chemical groups on to the adsorbent surfaces [26]. The process involved for $\mathrm{Pb}$ (II) adsorption are the following (El-Said, 2010):

$$
\begin{aligned}
& \mathrm{Pb}^{2+}+n \mathrm{H}_{2} \mathrm{O}=\mathrm{Pb}\left(\mathrm{H}_{2} \mathrm{O}\right)_{n}{ }^{2+} \\
& \mathrm{Pb}\left(\mathrm{H}_{2} \mathrm{O}\right)_{n}{ }^{2+}=\mathrm{Pb}\left(\mathrm{H}_{2} \mathrm{O}\right)^{n-1}+\mathrm{H}^{+} \\
& n \mathrm{~Pb}^{2+}+m \mathrm{H}_{2} \mathrm{O}=\mathrm{Pb}(\mathrm{OH})_{m}^{(2 n-m)}+m \mathrm{H}^{+}
\end{aligned}
$$

The maximum percent removal of $\mathrm{Pb}$ (II) was observed at $\mathrm{pH} 4$ and significantly decreased at higher $\mathrm{pH}$ values. Above $\mathrm{pH} \mathrm{4}$, the sorption yield decreases with increasing $\mathrm{pH}$ because hydrolysis and precipitation begin to play an important role in the sorption of $\mathrm{Pb}$ (II) (Yusan et al., 2012).

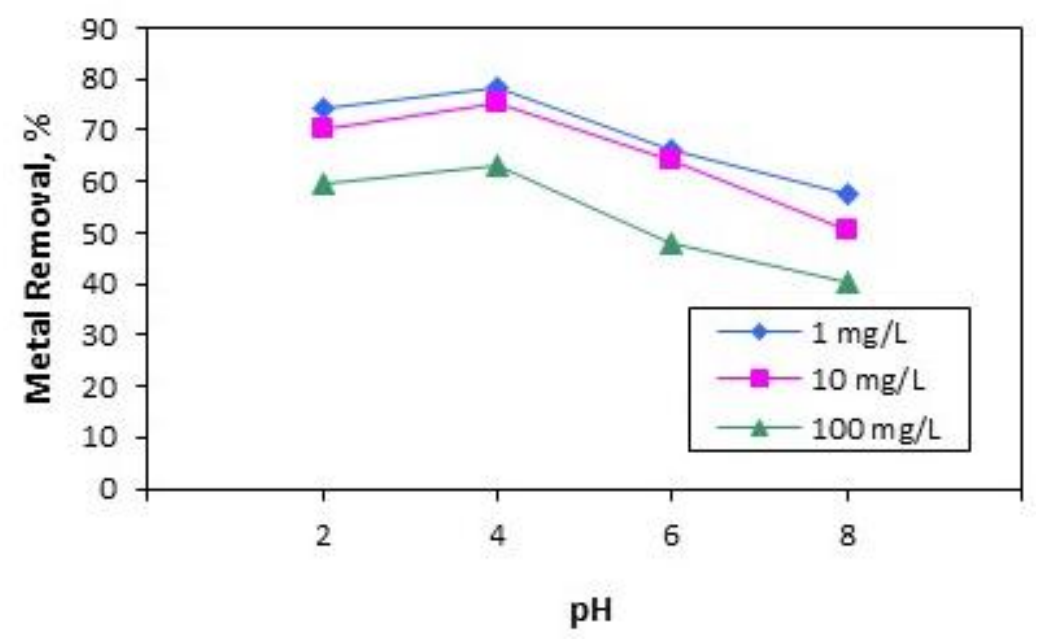

Figure 1. Effect of $\mathrm{pH}$ for the removal of $\mathrm{Pb}$ (II) onto diatomite

\subsection{Effect of adsorbent dosage}

The adsorbent dosage was varied from 2 to $10 \mathrm{~g} \mathrm{I}^{-1}$. The effect of the amount of diatomite on $\mathrm{Pb}$ (II) removal is presented in Fig. 2 and the removal of $\mathrm{Pb}$ (II) increases with increasing diatomite dosage.

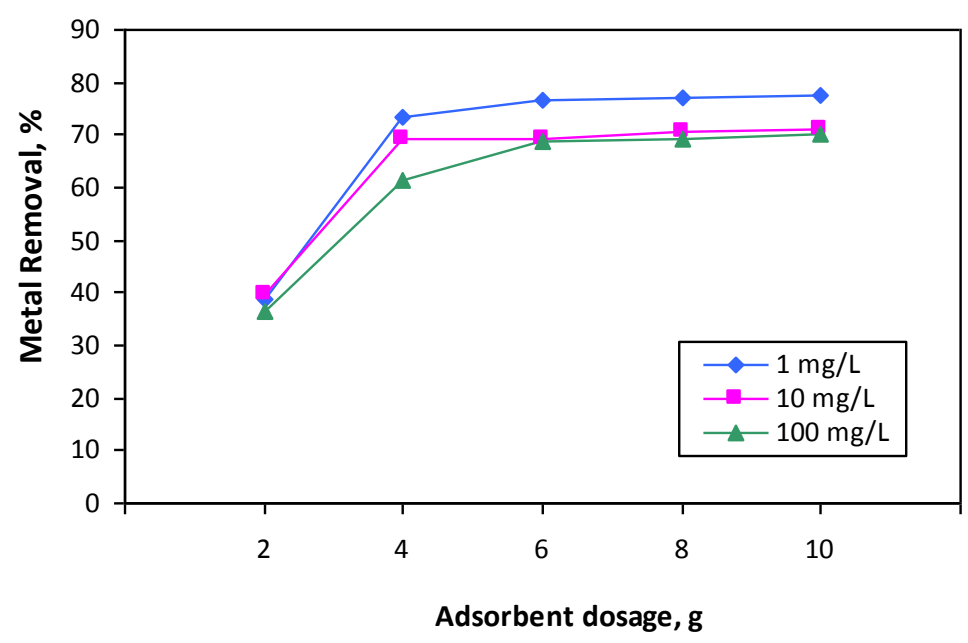

Figure 2. Effect of adsorbent dosage for the removal of $\mathrm{Pb}$ (II) onto diatomite

The $\mathrm{Pb}$ (II) removal was not changed significantly for $4 \mathrm{~g} \mathrm{I}^{-1}$ adsorbent dosage and higher. For this reason, the adsorbent dosage of diatomite for $\mathrm{Pb}$ (II) removal was determined to be $4 \mathrm{~g} \mathrm{I}^{-1}$ for further adsorption 
experiments. Similar observations were found $\mathrm{Pb}$ (II) removal using mineral adsorbents by Varank et al. (2014) and Rashed (2001).

\subsection{Effect of contact time}

The influence of contact time on the adsorption of $\mathrm{Pb}$ (II) ions onto diatomite was also investigated. In the experiments, optimum values of $\mathrm{pH}(4)$ and diatomite dosage $\left(4 \mathrm{~g} \mathrm{~L}^{-1}\right)$ were used for $\mathrm{Pb}$ (II) removal. The effect of contact time is shown in Fig. 3. The results reveal that the metal removal is higher at the beginning. This is likely due to the larger surface area of diatomite at the beginning for the adsorption of heavy metal ions. As the surface adsorption sites become exhausted, the uptake rate is controlled by the rate at which the adsorbate is transported from the exterior to the interior sites of the adsorbent particles (Dorrls et al., 2000; Bulut and Tez, 2007; Turan, 2010).

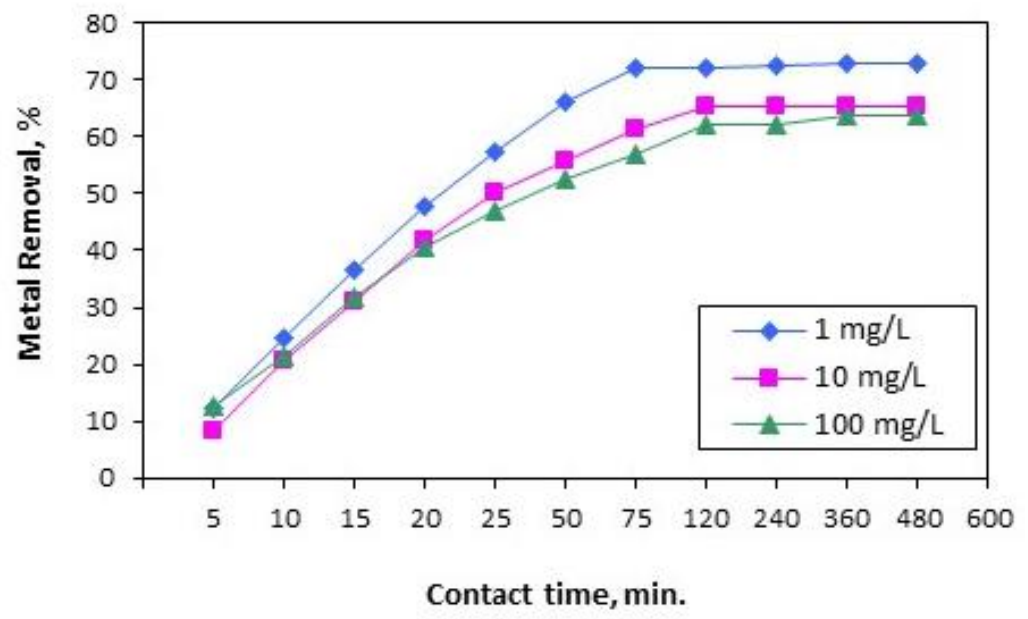

Figure 3. Effect of contact time for the removal of $\mathrm{Pb}$ (II) onto diatomite

The optimum contact time for $\mathrm{Pb}$ (II) removal was determined at 75 min. The removal rate of $\mathrm{Pb}$ (II) gradually decreased with increase in contact time. Initially, the rate of $\mathrm{Pb}$ (II) uptake was higher because all sites on the adsorbent were vacant and $\mathrm{Pb}$ (II) concentration was high, but decrease of sorption sites reduced the uptake rate. Similar results were found in the study of Mousavi et al. (2010) and Surchi (2011) (Mousavi et al., 2010; Surchi, 2011).

\subsection{Adsorption isotherms}

Sorption is a physical and/or chemical process in which a substance is accumulated at an interface between phases. A number of different equations can be used to predict theoretical adsorption capabilities for different adsorbents. For this study, Langmuir, Freundlich, and Dubinin-Radushkevic isotherm equations have been used to predict adsorption capabilities of metals on diatomite.

The Langmuir isotherm assumes that adsorption takes place at specific homogeneous sites within the adsorbent and has found successful applications in many adsorption processes of monolayer adsorption. The Langmuir isotherm is written as follows:

$q_{\mathrm{e}}=K_{\mathrm{L}} q_{\mathrm{m}} C_{\mathrm{e}} / 1+K_{\mathrm{L}} C_{\mathrm{e}}$

where $q_{\mathrm{m}}$ is the maximum monolayer adsorption capacity of the adsorbent $\left(\mathrm{mg} \mathrm{g}^{-1}\right)$, and $K_{\mathrm{L}}$ is the Langmuir adsorption constant $\left(\mathrm{L} \mathrm{mg}^{-1}\right)$, which is related to the free energy of adsorption.

Eq. (1) can be rearranged in the following linear form:

$C_{\mathrm{e}} / q_{\mathrm{e}}=1 / K_{\mathrm{L}} q_{\mathrm{m}}+C_{\mathrm{e}} / q_{\mathrm{m}}$

The plot of $C_{\mathrm{e}} / q_{\mathrm{e}}$ versus $C_{\mathrm{e}}$ gives a straight line with slope $1 / q_{\mathrm{m}}$, and intercept $1 / K_{\mathrm{L}} q_{\mathrm{m}}$. Fig. 4 presents the plot of $C_{\mathrm{e}} / q_{\mathrm{e}}$ vs $C_{\mathrm{e}}$ for the $\mathrm{Pb}$ (II) removal by adsorption onto diatomite. 
Freundlich isotherm is the oldest and most widely used adsorption equation for solid-liquid systems. The Freundlich isotherm has been derived by assuming an exponentially decaying sorption site energy distribution. This experimental model can be applied to non-ideal sorption on heterogenous surfaces as well as multilayer sorption. The empirically derived Freundlich isotherm is defined as follows:

$\mathrm{q}_{\mathrm{e}}=\mathrm{K}_{\mathrm{f}} \mathrm{C}_{\mathrm{e}}^{1 / \mathrm{n}}$

where $K_{\mathrm{f}}(\mathrm{L} / \mathrm{g})$ and $n$ (dimensionless) are the constants that can be related to the adsorption capacity and the adsorption nonlinearity intensity, respectively.

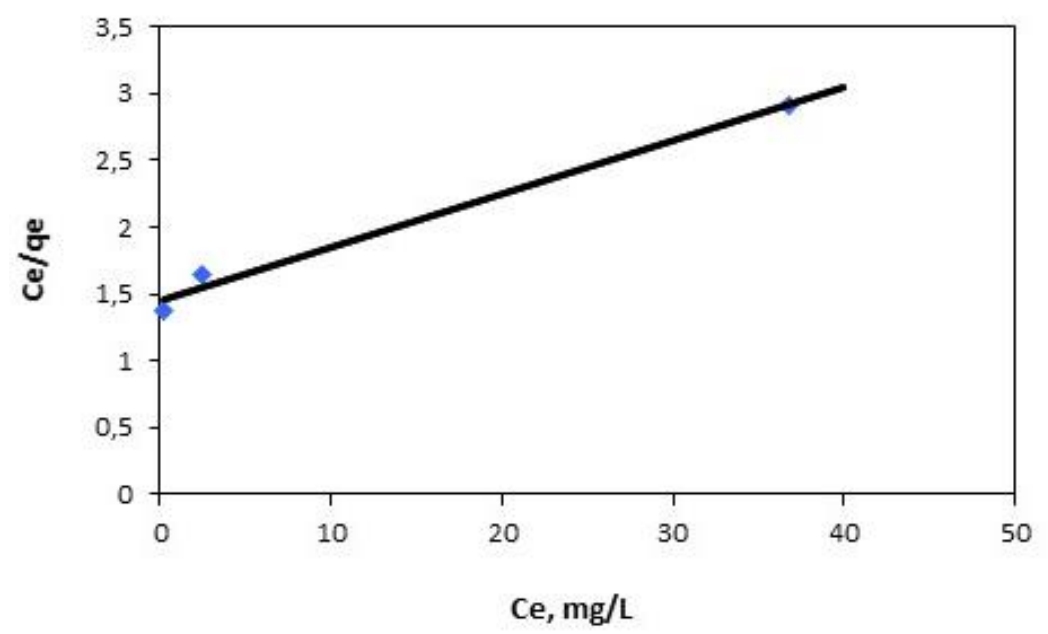

Figure 4. Langmuir plots for the adsorption of $\mathrm{Pb}$ (II) on diatomite, adsorbent dosage $=4 \mathrm{~g} \mathrm{I}^{-1}, \mathrm{pH} 4$, initial $\mathrm{Pb}$ (II) concentration=1-10-100 $\mathrm{mg}^{-1}, T=303.15$

This equation can be rearranged in the linear form by taking the logarithm of both sides as:

$\log q_{\mathrm{e}}=\log K_{\mathrm{f}}+1 / \mathrm{n} \log C_{\mathrm{e}}$

The values of $K_{\mathrm{f}}$ and $1 / n$ may be calculated by plotting $\log q_{\mathrm{e}}$ against $\log C_{\mathrm{e}}$. The slope is equal to $1 / n$ and the intercept is equal to $\log K_{\mathrm{f}}$. Fig. 5 presents the plot of $\log q_{\mathrm{e}}$ as a function of $\log C_{\mathrm{e}}$ for the $\mathrm{Pb}$ (II) removal.

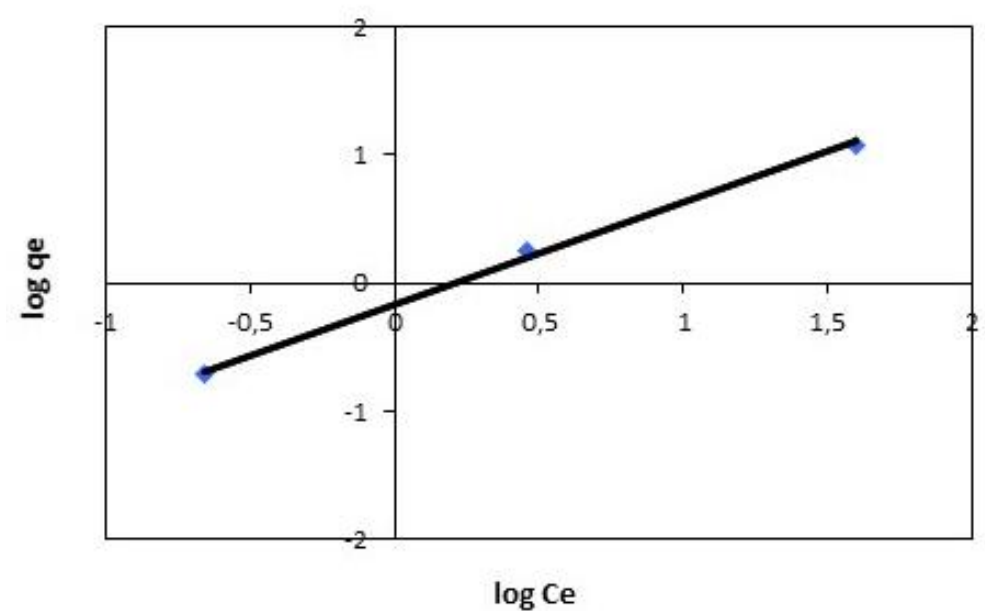

Figure 5. Freundlich plots for the adsorption of $\mathrm{Pb}$ (II) on diatomite, adsorbent dosage $=4 \mathrm{~g} \mathrm{l}^{-1}, \mathrm{pH} 4$, initial $\mathrm{Pb}$ (II) concentration=1-10-100 $\mathrm{mg} \mathrm{l}^{-1}, \mathrm{~T}=303.15$ 
Dubinin-Radushkevich ( $D-R$ ) proposed an equation for the analysis of isotherms in order to determine if the adsorption occurred by a physical or chemical process. The D-R equation is more general than the Langmuir model because it does not assume a homogeneous surface, a constant sorption potential, or an absence of steric hindrance between adsorbed and incoming particles:

$\ln \mathrm{qe}=\ln \mathrm{q}_{\mathrm{m}}-\beta \varepsilon^{2}$

where qe is the amount of metal cations adsorbed per $\mathrm{g}$ of biomass, $q_{\mathrm{m}}$ represents the maximum sorption capacity of the adsorbent, $\beta$ is a constant related to sorption energy ( $D-R$ constant), and $\varepsilon$ is the Polanyi sorption potential calculated by Eq. (9)

$\varepsilon=R T \ln \left(1+1 / C_{e}\right)$

where $C_{e}$ is the metal equilibrium concentration $\left(\mathrm{mg} \mathrm{l}^{-1}\right), R$ is the gas constant $\left(\mathrm{kJ} \mathrm{mol}^{-1} \mathrm{~K}^{-1}\right)$, and $\mathrm{T}$ is the temperature $(\mathrm{K})$. The Polanyi sorption approach assumes a fixed volume of sorption space close to the adsorbent surface and the existence of sorption potential over these spaces. The sorption space in the vicinity of a solid surface is characterized by a series of equipotential surfaces having the same sorption potential. This sorption potential is independent of the temperature but varies according to the nature of sorbent and sorbate (Areco et al., 2010). The slop of the plot of $\ln q_{e}$ versus $\varepsilon^{2}$ gives $\beta\left(\mathrm{mol}^{2} \mathrm{~J}^{-2}\right.$ ) and the intercept yields the sorption capacity, $\mathrm{q}_{\mathrm{m}}\left(\mathrm{mg} \mathrm{g}^{-1}\right)$ (Fig. 6).

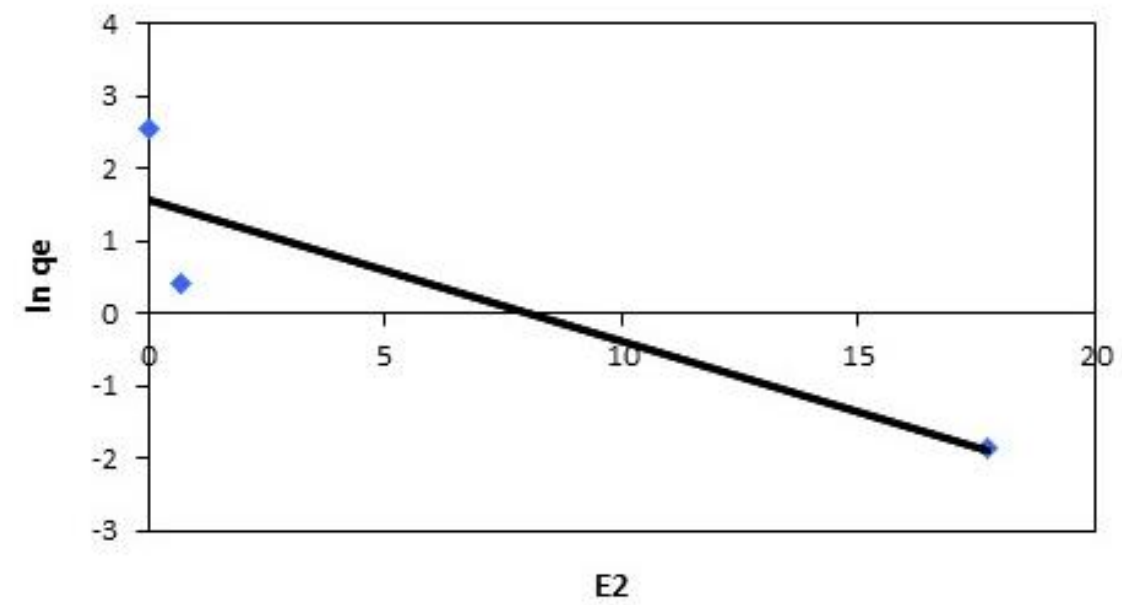

Figure 6. Dubinin-Radushkevich (D-R) plots for the adsorption of $\mathrm{Pb}(\mathrm{II})$ on diatomite, adsorbent dosage $=$ $4 \mathrm{~g} \mathrm{l}^{-1}, \mathrm{pH} 4$, initial $\mathrm{Pb}$ (II) concentration=1-10-100 $\mathrm{mg} \mathrm{l}^{-1}, \mathrm{~T}=303.15$

The Langmuir, Freundlich and Dubinin-Radushkevich isotherms parameters for the adsorption of $\mathrm{Pb}$ (II) ions onto diatomite are listed in Table 2.

Table 2. Langmuir, Freundlich, and Dubinin-Radushkevic isotherm constants for adsorption of $\mathrm{Pb}$ (II) onto diatomite

\begin{tabular}{cccccccccc}
\hline \multirow{2}{*}{$\mathbf{H}$} & \multicolumn{3}{c}{ Langmuir } & \multicolumn{3}{c}{ Freundlich } & \multicolumn{3}{c}{ Dubinin-Radushkevich } \\
\cline { 2 - 11 } & $\boldsymbol{q}_{\mathbf{m}}$ & $\boldsymbol{K}_{\mathrm{L}}$ & $\boldsymbol{R}^{\mathbf{2}}$ & $\boldsymbol{K}_{\mathbf{f}}$ & $\mathbf{1} \boldsymbol{n}$ & $\boldsymbol{R}^{\mathbf{2}}$ & $\boldsymbol{q}_{\mathbf{m}}$ & $\boldsymbol{\beta}$ & $\boldsymbol{R}^{\mathbf{2}}$ \\
\hline 2 & 26 & 0.53 & 0.972 & 0.62 & 0.85 & 0.997 & 4.8 & 0.19 & 0.793 \\
\hline 4 & 25 & 0.69 & 0.999 & 0.50 & 0.87 & 0.999 & 4.4 & 0.23 & 0.786 \\
\hline 6 & 19 & 0.39 & 0.988 & 0.36 & 0.85 & 0.995 & 3.8 & 0.30 & 0.802 \\
\hline 8 & 19 & 0.24 & 0.929 & 0.24 & 0.86 & 0.998 & 3.0 & 0.38 & 0.777 \\
\hline
\end{tabular}

When the $\mathrm{R}^{2}$ values are compared in Table 2, the Freundlich isotherm model fits better than the other isotherm models. The magnitudes of $K_{f}$ and $n$ show easy separation of $\mathrm{Pb}$ (II) ions from the aqueous solution and indicate favourable adsorption. The intercept $\mathrm{K}_{\mathrm{f}}$ value is an indication of the adsorption capacity of the adsorbent; the slope $1 / n$ indicates the effect of concentration on the adsorption capacity 
and represents adsorption intensity. In case of $n=1$ indicates linear adsorption and equal adsorption energies for all sites. Values of $n<1$ shows that the marginal adsorption energy decreases with increasing surface concentration. As seen from Table 2, $\mathrm{n}$ value (1.176) indicated the high bond strength between absorbate and adsorbent, and it also illustrated the adsorbent surface was heterogeneous. The Freundlich adsorption capacity of diatomite studied in this work is similar to the results observed for diatomite by other researchers (Jian et al., 2013; Çalişkan et al., 2011; Wang et al., 2014).

\subsection{Kinetic modeling}

In the present work, different kinetic models such as pseudo-second order equation, Elovich equation and intra-particle diffusion equation are used to describe the $\mathrm{Pb}$ (II) adsorption onto the diatomite.

The pseudo-second order reaction kinetic rate equation is expressed as (Ho, 2004):

$\frac{d q_{t}}{d t}=k_{2}\left(q_{e}-q_{t}\right)^{2}$

where $q_{\mathrm{e}}$ and $q_{\mathrm{t}}$ are the amount of heavy metal $\left(\mathrm{mg} \mathrm{g}^{-1}\right)$ adsorbed at equilibrium time and time $t(\mathrm{~d})$ and $k_{2}$ is the second order reaction constant $\left(\mathrm{g} \mathrm{mg}^{-1} \mathrm{~min}^{-1}\right)$, respectively. For the boundary conditions $q_{\mathrm{t}}=0$ to $q_{\mathrm{t}}=q_{\mathrm{t}}$ at $t=0$ to $t=t$; the integrated form of Eq. (7) becomes:

$\frac{t}{\mathrm{q}_{\mathrm{t}}}=\frac{1}{\mathrm{k}_{2} \mathrm{q}_{\mathrm{e}}^{2}}+\frac{1}{\mathrm{q}_{\mathrm{e}}} \mathrm{t}$

A straight line of $t / q_{t}$ versus $t$ indicates the application of the second order kinetic model. The values of $k_{2}$ are determined from the slope of the plots (Fig. 7).

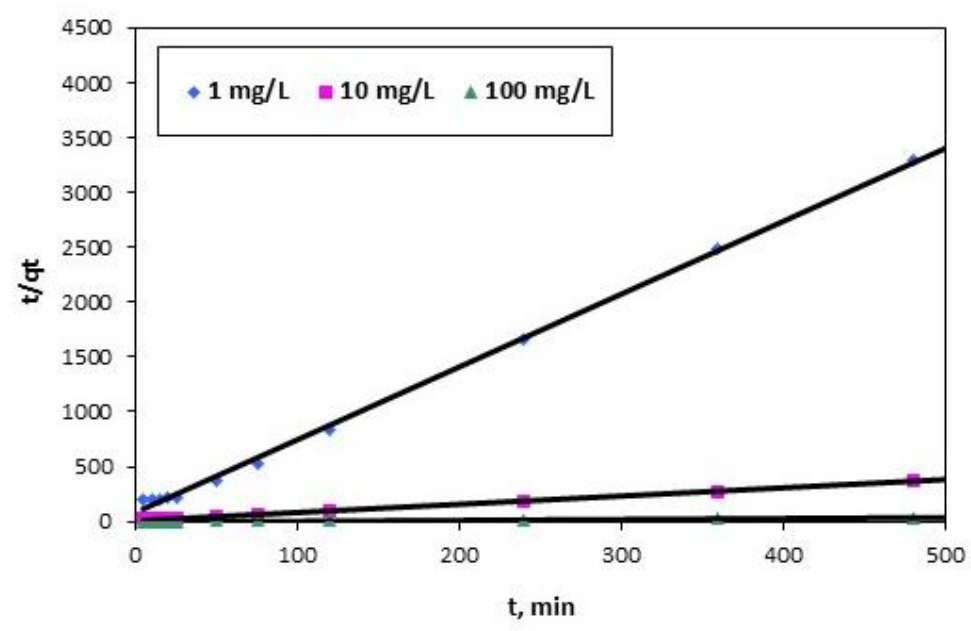

Figure 7. Pseudo-second order reaction kinetics for the adsorption of $\mathrm{Pb}$ (II) ion

The Elovich equation is expressed as follows (Low, 1960):

$$
\frac{d q_{t}}{d t}=\alpha \exp \left(-\beta q_{t}\right)
$$

where $\alpha$ is the initial adsorption rate $\left(\mathrm{mg} \mathrm{g}^{-1} \mathrm{~min}^{-1}\right)$ and $\beta$ is the desorption constant $\left(\mathrm{g} \mathrm{mg}^{-1}\right)$. To simplify the Elovich equation, Chien and Clayton (1980) assumed $\alpha \beta_{t} \gg>1$ and by applying the boundary conditions $\mathrm{q}_{\mathrm{t}}=0$ at $\mathrm{t}=0$ and $\mathrm{q}_{\mathrm{t}}=\mathrm{q}_{\mathrm{t}}$ at $\mathrm{t}=\mathrm{t} \mathrm{Eq}(12)$ becomes (Chien and Clayton, 1980; Sparks, 1999):

$\mathrm{q}_{\mathrm{t}}=\frac{1}{\beta} \ln (\alpha \beta)+\frac{1}{\beta} \ln \mathrm{t}$

A straight line plot of $q_{\mathrm{t}}$ versus $\ln t$ indicates the application of the Elovich model. The values of constants can be obtained from the slope and intercept of the plots (Fig. 8). 
The adsorbate transport from the solution phase to the surface of the adsorbent particles occurs in several steps. Generally, a process is diffusion controlled if its rate is dependent upon the rate at which components diffuse towards one another.

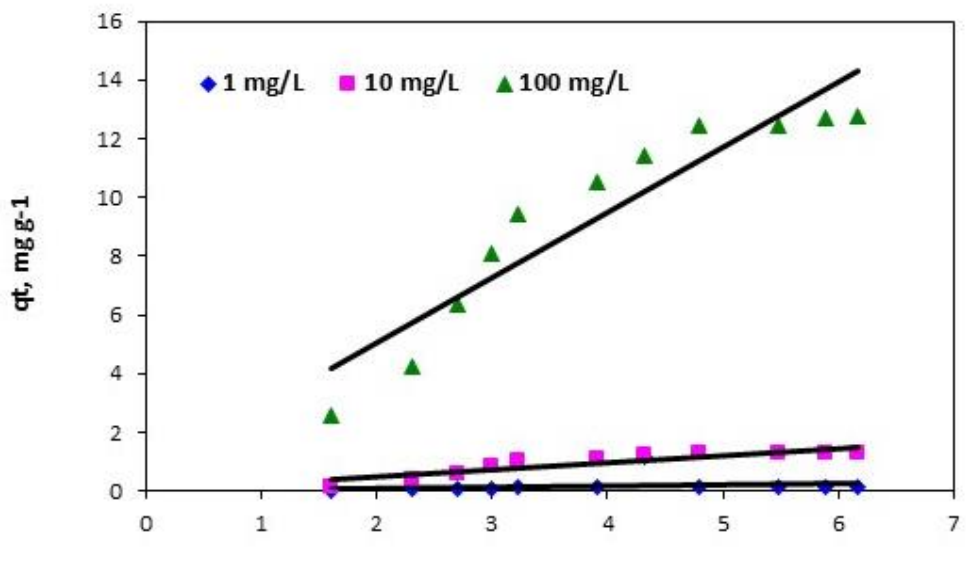

Int

Figure 8. Elovich kinetics for the adsorption of $\mathrm{Pb}$ (II) ion

The possibility of intra-particle diffusion was explored by using the intra-particle diffusion model as (Poots et al., 1978; Allen et al., 1989; Srihari and Das, 2008):

$\mathrm{q}_{\mathrm{t}}=\mathrm{K}_{\mathrm{id}} \mathrm{t}^{1 / 2}+\mathrm{C}$

where $K_{\text {id }}$ is the intra-particle diffusion rate constant $\left(\mathrm{mg} \mathrm{g}^{-1} \mathrm{~min}^{-1 / 2}\right)$ and $\mathrm{C}$ is the intercept. The values of $\mathrm{C}$ may indicate the thickness of the boundary layer, i.e., the larger intercept, the greater the boundary layer effect is (El-Ashtoukhy et al., 2008; Kanan and Sundaram, 2001).

A plot of $q_{\mathrm{t}}$ versus $t^{1 / 2}$ indicates the application of the intra-particle diffusion model. The values of $K_{\text {id }}$ were determined from the slope of the plots (Fig. 9).

The kinetic parameters of lead (II) onto diatomite are calculated from these plots and given in Table 3. Table 3 shows that the correlation coefficients $\left(R^{2}\right)$ for the Elovich and the intra-particle diffusion kinetic models are lower than the pseudo-second order kinetic model. Moreover, the calculated $q_{\mathrm{e}}$ values agree with experimental $q_{\mathrm{e}}$ values for the pseudo-second order kinetic model. It is probable that the adsorption system fits the pseudo-second order kinetic model. This indicates that for all the tested systems, the ratelimiting step is chemical sorption (chemisorption) between the adsorbents and the lead (II) ions.

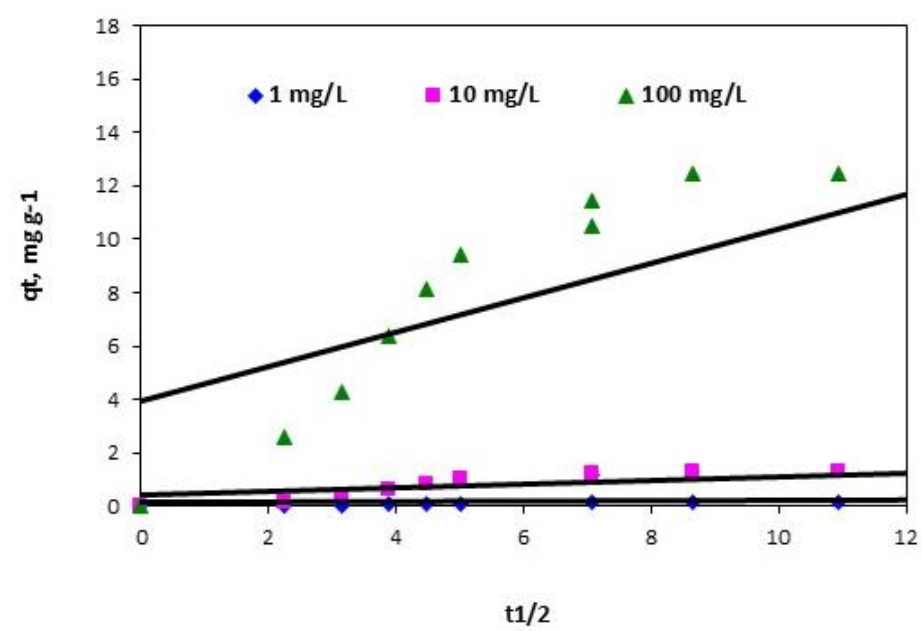

Figure 9. Intra-particle diffusion kinetics for the adsorption of $\mathrm{Pb}$ (II) ion 
Table 3. Adsorption kinetic parameters of $\mathrm{Pb}$ (II) onto diatomite

\begin{tabular}{cccc}
\hline Kinetic equation and parameter & $1 \mathrm{mg} \mathrm{l}^{-1}$ & $10 \mathrm{mg} \mathrm{l}^{-1}$ & $100 \mathrm{mg} \mathrm{l}^{-1}$ \\
\hline Second-order kinetic equation & & & \\
\hline $\mathrm{k}_{2}\left(\mathrm{~g} \mathrm{mg}^{-1} \mathrm{~min}^{-1}\right)$ & 0.53 & 0.047 & 0.005 \\
\hline $\mathrm{q}_{2}\left(\mathrm{mg} \mathrm{g}^{-1}\right)$ & 0.15 & 1.4 & 13 \\
\hline $\mathrm{R}^{2}$ & 0.998 & 0.997 & 0.999 \\
\hline Elovich equation & & \\
\hline$\alpha\left(\mathrm{mg} \mathrm{g}^{-1} \mathrm{~min}^{-1}\right)$ & 0.098 & 0.25 & 2.9 \\
\hline$\beta\left(\mathrm{g} \mathrm{mg}^{-1}\right)$ & 24 & 4.1 & 0.45 \\
\hline $\mathrm{R}^{2}$ & 0.409 & 0.837 & 0.876 \\
\hline Intra-particle diffusion equation & & \\
\hline $\mathrm{K}_{\text {id }}\left(\mathrm{mg} \mathrm{g}^{-1} \mathrm{~min}^{-1 / 2}\right)$ & 0.007 & 0.068 & 0.65 \\
\hline $\mathrm{R}^{2}$ & 0.154 & 0.635 & 0.671 \\
\hline
\end{tabular}

\section{Conclusions}

The following conclusions can be drawn:

- Adsorption of $\mathrm{Pb}$ (II) on diatomite is clearly affected by $\mathrm{pH}$. The maximum percent removal of $\mathrm{Pb}$ (II) was observed at $\mathrm{pH} 4$ and significantly decreased at higher $\mathrm{pH}$ values.

- $\mathrm{Pb}$ (II) removal is positively influenced by an increase in the adsorbent dosage. The maximum diatomite adsorption efficiencies for $\mathrm{Pb}$ (II) ion was obtained at the range of $70-77 \%$ for all concentrations studied.

- A time of 75 min was found for construction of the isotherms because the increment in contact time from 75 min to 480 min did not show any significant effect on efficiency.

- The adsorption isotherms of $\mathrm{Pb}$ (II) on diatomite can be described by the Freundlich model.

- The adsorption system fits the pseudo second order kinetic model.

- Diatomite was found to have a high adsorption capacity for removing lead (II) ion from aqueous solutions.

\section{References}

Aguado J., Arsuaga J.M., Arencibia A., Lindo M. and Gascón V. (2009), Aqueous heavy metals removal by adsorption on amine-functionalized mesoporous silica, Journal of Hazardous Materials, 163, 213-221.

Allen S.J., McKay G. and Khader K.Y.H. (1989), Intraparticle diffusion of a basic dye during adsorption onto Sphagnum Peat, Environmental Pollution, 56, 39-50.

Areco M.M. and Afonso M.S. (2010), Copper, zinc, cadmium and lead biosorption by Gymnogongrus torulosus. Thermodynamics and kinetics studies, Colloids and Surfaces B: Biointerfaces, 81, 620-628.

Axtell N.R., Sternberg S.P.K. and Claussen K. (2003), Lead and nickel removal using Microspora and Lemna minor, Bioresource Technology, 89, 41-48.

Bhattacharya A.K., Mandal S.N., and Das S.K. (2006), Adsorption of Zn (II) from aqueous solution by using different adsorbents, Chemical Engineering Journal, 123, 43-51.

Bulut Y. and Tez Z. (2007), Adsorption studies on ground shells of hazelnut and almond, Journal of Hazardous Materials, 149, 35-41.

Çalışkan N., Kul A.R., Alkan S., Gogut E.G. and Alacabey I. (2011), Adsorption of zinc (II) on diatomite and manganeseoxide-modified diatomite: A kinetic and equilibrium study, Journal of Hazardous Materials, 193, 27-36.

Cheremisinoff P.N. (1995), Handbook of Water and Wastewater Treatment Technology, Marcel Dekker Inc., New York. 
Chien S.H. and Clayton W.R. (1980), Application of Elovich equation to the kinetics of phosphate release and sorption in soils, Soil Sci. Soc. Am. J., 44, 265-268.

Dorrls K.L., Yu B., Zhang Y., Shukla A. and Shukla S.S. (2000), The removal of heavy metal from aqueous solutions by sawdust adsorption-removal of copper, Journal of Hazardous Materials, 80, 33-42.

El-Ashtoukhy E.S.Z., Amin N.K. and Abdelwahab O. (2008), Removal of lead (II) and copper (II) from aqueous solution using Pomegranate Peel as a new adsorbent, Desalination, 223, 162-173.

El-Bayaa A.A., Badawy N.A. and AlKhalik E.A. (2009), Effect of ionic strength on the adsorption of copper and chromium ions by vermiculite pure clay mineral, Journal of Hazardous Materials, 170, 1204-1209.

El-Said A.G. (2010), Biosorption of Pb (II) ions from aqueous solutions onto rice husk and its ash, Journal of American Science, 6(10), 143-150.

Ho Y.S. (2004), Citation review of Lagergreen kinetic rate equation on adsorption reaction, Scientometrics, 59, 171-177.

ljagbemi C.O., Baek M.H. and Kim D.S. (2009), Montmorillonite surface properties and sorption characteristics for heavy metal removal from aqueous solutions, Journal of Hazardous Materials, 166, 538-546.

Jian Z., Qingwei P., Meihong N., Haiqiang S. and Na L. (2013), Kinetics and equilibrium studies from the methylene blue adsorption on diatomite treated with sodium hydroxide, Applied Clay Science, 83-84, 12-16.

Kanan K. and Sundaram M.M. (2001), Kinetics and mechanism of removal methylene blue by adsorption on various carbons-a comparative study, Dyes Pigments, 51, 25-40.

Keskinkan O., Goksu M.Z.L., Basibuyuk M. and Forster C.F. (2004), Heavy metal adsorption properties of a submerged aquatic plant (Ceratophyllum demersum), Bioresource Technology, 92, 197-200.

Khraisheh M.A.M., Al-degs Y.S. and Mcminn W.A.M. (2004), Remediation of wastewater containing heavy metals using raw and modified diatomite, Chemical Engineering Journal, 99, 177-184.

Li Q., Wu S., Liu G., Liao X., Deng X., Sun D., Hu Y. and Huang Y. (2004), Simultaneous biosorption of cadmium (II) and lead (II) ions by pretreated biomass of Phanerochaete chrysosporium, Separation and Purification Technology, 34, 135-142.

Lin S.H. and Juang R.S. (2002), Heavy metal removal from water by sorption using surfactant-modified montmorillonite, Journal of Hazardous Materials, 92, 315-326.

Low M.J.D. (1960), Kinetics of chemisorption of gases on solids, Chemical Reviews, 60, 267-312.

Márquez G.E., Ribeiro M.J.P., Ventura J.M. and Labrincha J.A. (2004), Removal of nickel from aqueous solutions by clay-based beds, Ceramics International, 30(1), 111-119.

Mittal A., Mittal J. and Kurup L. (2006), Adsorption isotherms, kinetics and column operations for the removal of hazardous dye, Tartrazine from aqueous solutions using waste materials-Bottom Ash and De-Oiled Soya, as adsorbents, Journal of Hazardous Materials, B136, 567-578.

Mousavi H.Z., Hosseynifar A., Jahed V. and Dehghani S.A.M. (2010), Removal of lead from aqueous Solution using waste Tire Rubber Ash as an Adsorbent, Brazilian Journal of Chemical Engineering, 27(1), 79-87.

Oliveira E.A., Montanher S.F., Andrade A.D., Nobrega J.A. and Rollemberg M.C. (2005), Equilibrium studies for the sorption of chromium and nickel from aqueous solutions using raw rice bran, Process Biochemistry, 40, 3485-3490.

Poots V.J.P., McKay G. and Healy J.J. (1978), Removal of basic dye from effluent using wood as an adsorbent, J. Water Pollut. Control Fed., 50, 926-935.

Qdaisa H.A. and Moussab H. (2004), Removal of heavy metals from wastewater by membrane processes: a comparative study, Desalination, 164, 105-11. 